Asthma

\section{Farming and asthma}

\section{B Schenker}

\section{Where do we stand?}

A $t$ the beginning of the 20th century, farmers were believed to be healthier than the general population. Exposure to fresh countryside air and physical work were thought to be the source of this improved health. During the 20th century this agrarian myth was shown to be incorrect-farmers not only had significantly higher rates of mortality from occupational injuries, but they also had higher rates of many chronic diseases such as cardiovascular and chronic obstructive pulmonary disease. ${ }^{1}$ Higher rates of chronic diseases were observed despite the generally lower rates of cigarette smoking among farmers, suggesting that workplace exposures were contributing factors. ${ }^{2}$ In the 1980s and 1990s there was markedly increased attention to the occupational health of farmers, and to respiratory effects of agricultural exposures. These studies confirmed that farming causes a wide range of respiratory diseases, including airway diseases such as asthma and COPD, hypersensitivity pneumonitis, interstitial fibrosis, infectious pneumonias, and toxic injuries such as silo filler's disease and tracheo-bronchitis from numerous irritant chemicals. ${ }^{3}$ Indeed, the spectrum of respiratory diseases from agricultural exposures reads like a textbook of occupational lung disease, and is very different from many classic occupational lung diseases such as asbestosis that are associated with a narrow pulmonary response. ${ }^{4}$

The range of lung diseases resulting from agricultural work is not surprising when one looks at the breadth and high concentration of toxic exposures on the farm. Pulmonary toxins include organic dusts (animal, vegetable products, pollens), infectious agents (bacteria, fungi, viruses, mycobacterium), endotoxins and glucans, toxic chemicals (solvents, fuels, disinfectants), pesticides (paraquat, fungicides, organophosphates), gases from silos, welding and animal waste $\left(\mathrm{NH}_{3}, \mathrm{Cl}_{2}, \mathrm{H}_{2} \mathrm{~S}, \mathrm{CO}_{2}, \mathrm{CO}, \mathrm{NO}\right.$,

This editorial was inspired by an original article published in Thorax (Eduard W, Douwes J, Omenaas E, et al. Do farming exposures cause or prevent asthma? Results from a study of adult Norwegian farmers. Thorax 2004;59:381-6).
$\mathrm{NO}_{2}$, etc), inorganic dusts (silica, silicates, clays), fertilisers, and feed additives. Exposures to these agents occur at concentrations significantly higher than in other occupational settings or from ambient sources. For example, endotoxin concentrations from agricultural exposures are commonly observed in the thousands $\left(\mathrm{EU} / \mathrm{m}^{3}\right)$, one or two orders of magnitude higher than levels seen in industrial occupational settings. ${ }^{5}$ Similarly, inhalable particle concentrations of farmers are frequently over $5 \mathrm{mg} / \mathrm{m}^{3}$ and respirable particle concentrations of $1-5 \mathrm{mg} / \mathrm{m}^{3}$ are commonly seen, well above levels in other occupations and dwarfing ambient particle exposures. $^{67}$

While agricultural respiratory disease has been of interest to a relatively small group of investigators, general interest in the health of farming populations has diminished as the percentage of the population farming has declined in developed countries, now less than $2 \%$ in many countries. Replacement of farm families by hired farm workers, usually immigrants, did not alter the decreasing interest in this population. All of this changed at the end of the 20th century, at least from a scientific perspective. This resulted from the juxtaposition of two important observations. First, the incidence of asthma was unequivocally shown to be increasing around the world over the past four or five decades. ${ }^{8}$ Second, it was observed that children exposed to farming environments in early life had a reduced incidence of atopy and asthma. ${ }^{9-14}$ The observation of reduced asthma among children raised on a farm is a fascinating story, originating from the clinical observation that these children had fewer allergies, and subsequently being confirmed in several epidemiological studies. Numerous studies have confirmed lower rates of atopy among children raised on a farm, and additional, but not all, studies have observed lower rates of asthma. Critical observations from these studies include the farm exposures occurring in the first year of life, and exposures to farm animals. The so-called "hygiene hypothesis" has been suggested to explain the global increase in asthma, but that debate is beyond the scope of this editorial. ${ }^{15}$
More relevant is the apparent contradiction that exposures to farm environments in early life reduce the incidence of asthma, but adult exposures on the farm are a known cause of occupational asthma. One might refer to this as the "agricultural asthma paradox". There are many well described agricultural sensitisers causing asthma, including grain-dust mites, soya bean powder, cow epithelium, and various arthropod exposures. ${ }^{3}$ However, numerous respiratory irritants in agriculture cause an "asthma-like" syndrome, an acute non-allergic airway response arising from inhalation of various agents such as grain and cotton dust. Is the farm good or bad for asthma, or is timing everything? So far, there has been no clear answer to the question, but increasing attention to the issue is beginning to increase our understanding of this paradox.

Eduard and colleagues have analysed data on asthma from a Norwegian cohort of 2169 farmers. ${ }^{16}$ Asthma was determined by self-report, and atopy by positive RAST test. Additionally, exposures to major respiratory toxins were measured for different types of farming. Overall the prevalence of current asthma was low $(2.7 \%)$, probably in part reflecting the well described healthy worker effect among farmers. ${ }^{17}$ Most interesting was the observation that only $20 \%$ of farmers with asthma were atopic, and asthma in atopic farmers was significantly less prevalent among farmers of $\geqslant 2$ types of livestock. Conversely, asthma among non-atopic farmers was significantly increased among those who farmed $\geqslant 2$ types of livestock. Analysis of specific exposures suggested that fungal spores were more significantly associated with reduced asthma in atopic farmers than endotoxin or ammonia, but this analysis was likely limited by the low prevalence of asthma and collinearity of exposures.

These findings are important because they suggest some insight into the agricultural asthma paradox. Early farm exposures, especially those in the first year of life, reduce the incidence of atopy and atopic asthma, and exposures later in life increase the risk of nonatopic asthma. Careful study of nonatopic asthma among farmers and agricultural workers may reveal frequent occurrence of the "asthma-like syndrome" resulting from numerous agricultural exposures to respiratory irritants. The specific exposures responsible for reduced atopic asthma remain to be identified, although they appear to be most strongly associated with livestock farming, and not with crop farming. For the adult farmer, exposure to respiratory irritants is a significant risk factor for non-atopic asthma. Atopic asthma from 
exposure to well known agricultural antigens also exists, although it may be much less common than non-atopic asthma among farmers.

As the farm continues to be an important laboratory for understanding the causes, and possibly prevention, of asthma, it is important to remember that agriculture is still the most common occupation in the world, and many respiratory diseases including asthma are caused by exposures on the farm. As with all diseases, primary prevention is the preferred approach to reduce disease morbidity. On the farm this involves reducing exposures to many known respiratory toxins, an area of work in which there has been some recent progress in engineering controls, ${ }^{18}$ but in which progress is difficult because of farmer behaviours. ${ }^{19}$ Insights into the hygiene hypothesis should not decrease efforts to prevent the large burden of asthma and other respiratory diseases among farmers and other agricultural workers.

Occup Environ Med 2005;62:211-212.

doi: 10.1136/oem.2004.019109

Correspondence to: Prof. M B Schenker, Dept of Public Health Sciences, University of California at Davis, TB 168 Davis, CA 95616-8638, USA; mbschenker@ucdavis.edu

\section{REFERENCES}

1 Schenker MB. Preventive medicine and health promotion are overdue in the agricultural workplace. J Public Health Policy 1996;17:275-305.

2 Brackbill RM, Cameron LL, Behrens V. Prevalence of chronic diseases and impairments among US farmers, 1986-1990. Am J Epidemiol 1994;139:1055-65.

3 Schenker M. Respiratory health hazards in agriculture. In: Schenker M, ed. Am J Respir Crit Care Med 1998:S1-76.

4 Harber P, Schenker MB, Balmes JR, eds. Occupational and environmental respiratory disease. St Louis: Mosby, 1995

5 Clark S, Rylander R, Larsson L. Airborne bacteria, endotoxin and fungi in dust in poultry and swine confinement buildings. Am Ind Hyg Assoc J 1983;44:537-41.

6 Nieuwenhuijsen MJ, Noderer KS, Schenker MB, et al. Personal exposure to dust, endotoxin and crystalline silica in California agriculture. Ann Occup Hyg 1999;43:35-42.

7 Nieuwenhuijsen MJ, Kruize H, Schenker MB. Exposure to dust and its particle size distribution in California agriculture. Am Ind Hyg Assoc J 1998;59:34-8.

8 von Mutius E, Martinez FD. Epidemiology of childhood asthma. New York: Marcel Dekker 1999

9 Ernst P, Cormier Y. Relative scarcity of asthma and atopy among rural adolescents raised on a farm. Am J Respir Crit Care Med 2000;161:1563-6.
10 Riedler J, Eder W, Oberfeld G, et al. Austrian children living on a farm have less hay fever, asthma and allergic sensitization. Clin Exp Allergy 2000;30:194-200.

11 Von Ehrenstein OS, Von Mutius E, Illi S, et al. Reduced risk of hay fever and asthma among children of farmers. Clin Exp Allergy 2000:30:187-93.

12 Downs SH, Marks GB, Mitakakis TZ, et al. Having lived on a farm and protection against allergic diseases in Australia. Clin Exp Allergy 2001:31:570-5.

13 Klintberg B, Berglund N, Lilia G, et al. Fewer allergic respiratory disorders among farmers' children in a closed birth cohort from Sweden. Eur Respir J 2001;17:1151-7.

14 Braun-Fahrlander C. Environmental exposure to endotoxin and other microbial products and the decreased risk of childhood atopy: evaluating developments since April 2002. Curr Opin Allergy Clin Immuno 2003:3:325-9.

15 von Mutius E. Pro: the increase in asthma can be ascribed to cleanliness. Am J Respir Crit Care Med 2001;164:1106-9.

16 Eduard W, Douwes J, Omenaas E, et al. Do farming exposures cause or prevent asthma? Results from a study of adult Norwegian farmers. Thorax 2004;59:381-6.

17 Post W, Heederik D, Houba R. Decline in lung function related to exposure and selection processes among workers in the grain processing and animal feed industry. Occup Environ Med 1998:55:349-55.

18 Senthilselvan A, Zhang Y, Dosman JA, et al. Positive human health effects of dust suppression with canola oil in swine barns. Am J Respir Crit Care Med 1997;156(2 pt 1):410-17.

19 Schenker MB, Orenstein MR, Samuels SJ. Use of protective equipment among California farmers. Am J Ind Med 2002;42:455-64.

\section{The role of occupation in the development of chronic obstructive pulmonary disease (COPD)}

\section{Meldrum, R Rawbone, A D Curran, D Fishwick}

\section{A discussion of current issues}

C hronic obstructive pulmonary disease (COPD) is the fourth leading cause of death worldwide. ${ }^{1}$ In the UK, COPD is given as the cause of death on about 30000 death certificates annually. ${ }^{2}$ This represents $5.1 \%$ of all deaths. The prevalence of COPD is difficult to determine because the condition does not usually manifest until mid-life, when it is already moderately advanced. In England and Wales, it is estimated that there are currently 900000 diagnosed cases, and allowing for under-diagnosis the true prevalence is estimated to be 1.5 million. ${ }^{3}$ The total annual cost to the National Health Service for the treatment of COPD is thought to be $£ 491652000$ in direct costs, and $£ 982000000$ including indirect costs, causing 21.9 million working days to be lost in 1994-95 as a result of this condition

A recent clinical study from the UK noted that in a random sample of COPD patients, $44 \%$ were below retirement age, and $24 \%$ reported that they were completely prevented from working by their disease. ${ }^{4} \mathrm{~A}$ further $9 \%$ were limited in their ability to work, and patient carers also missed time from work. Established disease clearly interferes with work capability.

Cigarette smoking is undoubtedly the main cause of COPD in the population, but the link between harmful workplace exposures and COPD has been debated for many decades. Indeed, awareness of a link between work in dusty trades and chronic bronchitis (termed industrial bronchitis $^{5}$ ) can be traced back to the 19th century. In 1984, the US Surgeon General's report concluded that the only accepted cause of COPD was tobacco smoke; occupational exposures were characterised as putative rather than established causes. ${ }^{6}$ Since 1993 British coalminers with chronic bronchitis and emphysema (COPD) have been eligible for compensation if they have worked underground for at least 20 years. ${ }^{7}$ This would appear to acknowledge coalmine dust as a cause of COPD. This conclusion was subsequently endorsed following deliberations by the High Court in 1999, although not without controversy. In toxicological terms, there is nothing particularly harmful about coalmine dust compared to other workplace dusts, the key difference perhaps relating simply to generally higher and more prolonged exposures compared to most "above-ground" exposures. Certainly there is biological plausibility to the view that daily inhalation exposures over many years to high enough concentrations of dusts and irritants could cause lung damage eventually predisposing to COPD.

While the evidence for occupational exposures and asthma is more 
substantial, there is growing evidence from large population based studies in a number of countries suggesting that a sizeable proportion of the cases of COPD in society may be attributable to workplace exposures to dusts, noxious gases/ vapours, and fumes (DGVFs), the socalled "occupational COPD effect". The excess of COPD found in a DGVF exposed group (after correcting for smoking and other confounders) is calculated as the attributable risk due to these exposures. If the proportion of DGVF exposed workers in the general population is known or can be estimated, the population attributable risk (PAR) can be determined. For example, in one recent study of 9823 subjects aged 30-75 years randomly sampled from the US population, $693(7.1 \%)$ were identified as having COPD. ${ }^{8}$ Based on an analysis of the industries and occupations from which all 9823 subjects were drawn, and taking into account confounders such as smoking, age, sex, and socioeconomic status, the authors estimated that the population burden of COPD due to occupational exposure to DGVFs was $19.2 \%$. In nonsmokers, the proportion of work related COPD was estimated at $31 \%$.

The American Thoracic Society (ATS) ${ }^{9}$ recently produced a consensus statement based on an evaluation of a number of large scale general population studies, and calculated PARs for both COPD and asthma. From these studies it was calculated that the PAR\% for both asthma and COPD was about $15 \%$. None of the supporting studies assessed by the American Thoracic Society were conducted in the UK (as no appropriate UK studies exist).

It should be noted that in some of the large scale general population studies assessed by the American Thoracic Society, the original aim was to determine the overall impact of workplace exposures on the population burden of COPD, and not necessarily to identify workplace specific causes. However, in certain studies, information was sought on the specific substances and occupations associated with increased prevalences of COPD. Occupations linked to increased prevalences of COPD include construction, ${ }^{81011}$ leather, rubber, plastics manufacturing, ${ }^{8}$ plastics and rubber workers, ${ }^{10}$ textiles, ${ }^{8} 12$ food products, ${ }^{8}{ }^{10} 13$ spray painters, ${ }^{10}$ and welders. ${ }^{10}$ Specific substances linked to higher prevalences of COPD include quartz, ${ }^{11}{ }^{14}$ welding fumes, ${ }^{15}$ wood dust, ${ }^{15}$ sawdust, ${ }^{12}$ asbestos, ${ }^{11}{ }^{14}$ and solvents. ${ }^{11}$

Further data are available from the European Community Respiratory Health Survey, ${ }^{16}$ using pooled data from 14 industrialised countries. Exposure to vapours, gases, dust, or fumes was associated with an increased prevalence ratio of chronic bronchitis in smokers. Individuals associated with this increased risk were agricultural, textile, paper, wood, chemical, and food processing workers. Again, data from the New Zealand component of the ECRHS ${ }^{17}$ also noted an association with self-reported exposure to dust, vapours, fumes, and gases and both chronic bronchitis and airways obstruction. This study was limited to subjects under 45 years old, and identified bakers and spray painters at an increased risk.

Similarly, a large Norwegian study ${ }^{10}$ identified exposures to quartz, metal gases, aluminium production and processing, and welding as being significantly associated with airways obstruction after adjusting for sex, age, and smoking. In addition, exposure to quartz and asbestos was significantly associated with airways obstruction in those over 50 years old. This study also noted an overall effect of significant harmful exposure in the workplace (odds ratio $3.6,95 \%$ confidence interval 1.3 to 9.9) on the development of obstructive airways disease in comparison to nonexposed individuals. A study based in Northern Italy ${ }^{14}$ confirmed these findings and documented a causal association between occupational exposure and chronic obstructive pulmonary disease.

While cigarette smoking and occupational exposures appear to account in combination for the major proportion of the population attributable risk of COPD, other influences are potentially important. The understanding of genetic susceptibility to this condition is still in its relative infancy, but certain data do suggest genetics influences may be important, ${ }^{18}$ when considering both established disease and accelerated annual decline in $\mathrm{FEV}_{1}$. Furthermore, interactions have been noted between $\alpha_{1}$ anti-trypsin deficiency and environmental exposures in the development of COPD. ${ }^{19}$

Despite the above level of evidence, very little population data exist relating to the situation in the UK. One reason for this may be that, unlike occupational asthma, COPD tends not to be reported via national occupational health surveillance schemes such as SWORD ${ }^{20}$ (Surveillance of Work-related Occupational Respiratory Disease). This clearly reflects the clinical difficulties in attributing workplace causation for an individual patient with COPD, particularly as the majority have also smoked cigarettes. This is further compounded by the fact that COPD develops slowly, so that current cases of potential work related COPD are likely to reflect workplace exposures over the previous few decades.
As a result of these issues being recently highlighted, the Health and Safety Executive is now considering a more widely based strategy to reduce the impact of occupational respiratory disease in addition to its publicised occupational asthma strategy ${ }^{21}$ for which a programme of work is underway. ${ }^{22}$ There now appears to be a reasonable evidence base to support harmful occupational exposures as an independent cause of COPD. As such, regulators and occupational health professionals now need to consider what actions will be required to reduce relevant exposures. Indeed, reducing harmful workplace exposures may be practically easier in certain circumstances than smoking cessation.

Urgent research priorities include establishing the baseline domestic situation, as there is a lack of any relevant UK population data, while also concentrating on achieving and maintaining good practical workplace interventions to reduce harmful dust exposure. The term "nuisance dust", used to classify certain low toxicity dusts without a specific workplace occupational exposure limit, is misleading at best, and potentially gives false reassurance to workers and employers. This term should be revisited. In addition, the UK Control of Substances Hazardous to Health (COSHH) Regulations state that any dust not otherwise classified as harmful should be regarded as hazardous to health at airborne concentrations of 4 and $10 \mathrm{mg} / \mathrm{m}^{3}$ (respirable and inhalable fractions respectively). These levels almost certainly need to be lowered. The financial burden of COPD alone to our country should supply incentive to all those in positions of responsibility, irrespective of the personal and medical costs. Even if one assumes a relatively conservative estimate, $10 \%$ of the current approximate costs of the medical treatment of COPD in the UK equates to $£ 100$ million, and this does not take into account productivity losses due to working days lost.

Occup Environ Med 2005;62:212-214. doi: 10.1136/oem.2004.015511

\section{Authors' affiliations \\ M Meldrum, R Rawbone, A D Curran,}

D Fishwick, Health and Safety Laboratory and University of Sheffield, UK

Correspondence to: $\operatorname{Dr} D$ Fishwick, Health and Safety Laboratory and University of Sheffield, Harpur Hill, Buxton SK17 9JN, UK; david.fishwick@hsl.gov.uk

\section{REFERENCES}

1 European Respiratory Society and the European Lung Foundation. Lung health in Europe. Facts \& figures. "European Lung White Book". European 
Respiratory Society and European Lung Foundation, 2003.

2 Health and Safety Executive. Epidemiology and Medical Statistics Unit Mortality Databank-data compiled from death statistics from the Office for National Statistics and the General Register Office for Scotland.

3 Anon. Chronic obstructive pulmonary disease. NICE clinical guideline on management of chronic obstructive pulmonary disease in adults in primary and secondary care. Thorax 2004;59(suppl 1):1-232.

4 Britton $M$. The burden of COPD in the UK: results from the Confronting COPD survey. Respir Med 2003;97(suppl C):571-9.

5 Trupin L, Earnest G, San Pedro M, et al. The occupational burden of chronic obstructive pulmonary disease. Eur Respir J 2003;22:462-9.

6 Becklake M. Occupational exposures: evidence for a causal association with chronic obstructive pulmonary disease. Am Rev Respir Dis 1989:140:S85-91.

7 Coggon D, Newman Taylor M. Coal mining and chronic obstructive pulmonary disease: a review of the evidence. Thorax 1998:53:398-407.

8 Hnizdo E, Sullivan PA, Moon Bang K, et al. Association between chronic obstructive pulmonary disease and employment by industry and occupation in the US population: a study of data from the Third National Health and Nutrition Examination Survey. Am J Epidemiol 2002;156:738-46.

9 American Thoracic Society. American Thoracic Society Statement: Occupational contribution to the burden of airway disease. Am J Respir Crit Care Med 2003; 167:787-97.

10 Bakke PS, Baste V, Hanoa R, et al. Prevalence of obstructive lung disease in a general population: relation to occupational title and exposure to some airborne agents. Thorax 1991;46:863-70

11 Lebowitz MD. Occupational exposures in relation to symptomatology and lung function in a community population. Environ Res 1977; 14:59-67.

12 Sunyer J, Kogevinas M, Kromhout H, et al. Pulmonary ventilatory defects and occupational exposures in a population-based study in Spain Am J Respir Crit Care Med 1998;157:512-17.

13 Krzyzanowski M, Jedrychowski W. Occupational exposure and incidence of chronic respiratory symptoms among residents of Cracow followed for 13 years. Int Arch Occup Environ Health 1990;62:311-17.

14 Viegi G, Prediletto R, Paoletti P, et al. Respiratory effects of occupational exposure in a general population sample in north Italy. Am Rev Respir Dis 1991; 143:510-15.

15 Post WK, Heederik D, Kromhout $\mathrm{H}$, et al Occupational exposures estimated by a population specific job exposure matrix and 25 year incidence rate of chronic non-specific lung disease (CNSLD): the Zutphen Study. Eur Respir J 1994;7:1048-55.

16 Zock JP, Sunyer J, Kogevinas M, et al. Occupation, chronic bronchitis, and lung function in young adults. An international study. Am J Respir Crit Care Med 2001; 163:1572-7.

17 Fishwick D, Bradshaw LM, D'Souza W, et al. Chronic bronchitis, shortness of breath, and airway obstruction by occupation in New Zealand. Am J Respir Crit Care Med 1997; 156:1440-6.

18 Molfino NA. Genetics of COPD. Chest 2004: 125:1929-40.

19 Piitulainen E, Tornling G, Eriksson S Environmental correlates of impaired lung function in non-smokers with severe alpha 1 . antitrypsin deficiency (PiZZ). Thorax 1998:53:939-43.

20 Meredith SK, Taylor VM, McDonald JC Occupational respiratory disease in the United Kingdom 1989: a report to the British Thoracic Society and the Society of Occupational Medicine by the SWORD project group. $\mathrm{Br} J$ Ind Med 1991;48:292-8.

21 Curran AD, Fishwick D. Occupational asthma: research, change and the $30 \%$ target. Ann Occup Hyg 2003;47:433-6.

22 http://www.hse.gov.uk/asthmalwork.htm.

Answers to multiple choice questions on Design of exposure questionnaires for epidemiological studies by M J Nieuwenhuijsen, on pages 272-280

(1) $c$

(2) $a, b, d$

(3) $b$

(4) $a$

(5) $a$, and perhaps $b$

(6) $a, b, d$, and often c

(7) $b$ 